\title{
Utilização de modelos de norma de reação com variância residual heterogênea para estudo de valores genéticos de peso de codornas de corte em função de níveis de proteína bruta na dieta
}

\author{
[Using reaction norm models with heterogeneous residual variance to study genetic values of meat \\ type quail weight in function of crude protein levels of diet]
V.P.S. Felipe $e^{1,3}$, M.A. Silva $a^{2,3}$, R.R. Wenceslau ${ }^{1}$, B.D. Valente ${ }^{1}$, G.G. Santos ${ }^{1,3}$, L.S. Freitas ${ }^{1}$, G.S.S. Corrêa $a^{2,3}$, A.B. Corrêa $a^{2,3}$ \\ ${ }^{1}$ Aluno de pós-graduação - EV-UFMG - Belo Horizonte, MG \\ ${ }^{2}$ Escola de Veterinária - UFMG - Belo Horizonte, MG \\ ${ }^{3}$ Bolsista do $\mathrm{CNPq}$
}

\begin{abstract}
RESUMO
Avaliou-se a sensibilidade dos valores genéticos do peso de codornas de corte, mensurados ao $21^{\circ}$ e $35^{\circ}$ dias de idade, a dietas contendo diferentes níveis de proteína bruta. Observações obtidas de animais provenientes de duas linhagens (EV1 e EV2) foram utilizadas no ajuste de modelos de regressão aleatória, considerando-se heterogeneidade de variância residual. Os coeficientes de regressão aleatória do intercepto $\left(b_{0}\right)$ e linear $\left(b_{1}\right)$ apresentaram correlação positiva entre si em todas as análises, porém a linhagem EV2 apresentou maior magnitude dos valores deste parâmetro para ambas as idades. Houve heterogeneidade de variância genética aditiva e alteração na herdabilidade com a mudança no nível proteico da dieta para ambos os grupos genéticos e em todas as idades avaliadas. As normas de reação do grupo EV1 indicam presença de interação entre genótipo e ambiente $(\mathrm{G} \times \mathrm{E})$ em ambas as idades, com alteração na ordem dos efeitos genéticos de peso em função do nível proteico da dieta. Modificação da dispersão dos valores genéticos em função do nível de proteína indica presença de $\mathrm{G}$ x $\mathrm{E}$ na linhagem EV2. Portanto, a avaliação genética de codornas de corte sob dietas contendo determinado nível de proteína bruta não permite a predição de valores genéticos para outros níveis proteicos da dieta.
\end{abstract}

Palavras-chave: interação genótipo-ambiente, regressão aleatória, avaliação genética, codornas de corte

\begin{abstract}
The sensitivity of genetic values for body weight of meat type quails predicted at 21 and 35 days of age under diets with different crude protein levels was evaluated. Data from subjects belonging to two strains (EV1 and EV2) were used to fit a random regression model under heterogeneity of residual variance assumption. The random regression coefficients for intercept $\left(b_{o}\right)$ and slope $\left(b_{1}\right)$ were positively correlated in all analyses results, but the correlation was higher in the EV2 data analyses for both ages. Results indicated that additive genetic variance and heritability change as a function of the environment gradient for both genetic strains and ages. The reaction norms for EVI strain suggest there is genotype by environment interaction $(G \times E)$ for both ages as there were remarkable changes in the ranking of body weight breeding values for different crude protein levels. Furthermore, changes in the magnitude of the genetic effects dispersion as a function of protein level of diet indicates there is $G x E$ in EV1 and EV2 strains. Therefore, the prediction of breeding values for body weight of quails under a specific level of crude protein in the diet does not hold for different environments regarding the level of this nutrient.
\end{abstract}

Keywords: genotype by environment interaction, random regression, genetic evaluation, meat type quails

Recebido em 26 de abril de 2012

Aceito em 1 de agosto de 2012

E-mail: vivianfelipe@hotmail.com 


\section{INTRODUÇÃO}

A proteína é o componente mais caro utilizado na formulação de dietas para codornas de corte, portanto tem grande impacto sobre o custo de programas de seleção. Pode-se diminuir este custo pela utilização de dietas com níveis mais baixos de PB do que o adotado para codornas destinadas à produção comercial.

Diferenças na sensibilidade dos indivíduos às mudanças de ambiente resultam na interação genótipo-ambiente (GXE) (Falconer e MacKay, 1996). Desta maneira, se existe GXE para determinada característica, a diferença esperada entre fenótipos de indivíduos com genótipos distintos pode não ser a mesma em ambientes diferentes (Kolmodin, 2003). Sendo assim, progênies de codornas de corte avaliadas sob dietas com determinado nível de PB não teriam o mesmo desempenho em relação à média da população se alimentadas com dietas contendo nível diferente de $\mathrm{PB}$, podendo ocorrer até mesmo mudança na ordem de classificação dos valores genéticos estimados para diferentes níveis proteicos. Neste caso, a predição do valor genético do animal deve ser feita sob nível nutricional semelhante ao que é utilizado em criação comercial.

O estudo dessas diferenças na sensibilidade dos valores genéticos pode ser feito utilizando-se norma de reação, que é conceitualmente definida como a mudança sistemática na expressão média de uma característica fenotípica que ocorre em resposta à mudança sistemática de uma variável ambiental (Jong, 1990), isto é, o fenótipo expresso a partir de um genótipo é função do ambiente. Para a predição dela, são utilizados modelos de regressão aleatória (Kirkpatrick et al.,1990) que consideram as características como funções contínuas de um gradiente ambiental. Além da modelagem de características usando funções polinomiais, os modelos de regressão aleatória permitem que seja considerada a heterogeneidade de variância residual em cada classe ou até mesmo modelagem do resíduo por meio de função polinomial. Considerar variâncias residuais heterogêneas pode ter impacto positivo sobre a partição da variação total, resultando, assim, em incremento na qualidade das estimativas. Entretanto, modelos que consideram heterogeneidade residual contêm quantidade maior de parâmetros e, por consequência, suas matrizes de incidência são mais complexas, o que pode dificultar a convergência na estimação dos componentes de variância, principalmente no caso de banco de dados com número elevado de informações.

Portanto, o objetivo deste estudo foi avaliar a existência de interação genótipo-ambiente em codornas de corte EV1 e EV2 em duas idades $\left(21^{\circ}\right.$ e $35^{\circ}$ dias de idade), alimentadas com dietas contendo diferentes níveis de proteína bruta, por meio de modelos de regressão aleatória, considerando-se heterogeneidade de variância residual entre classes.

\section{MATERIAL E MÉTODOS}

As informações utilizadas neste estudo foram provenientes do Setor de Coturnicultura da Escola de Veterinária da UFMG, localizado em Igarapé - MG. Progênies de 100 reprodutores e 200 reprodutrizes de cada linhagem (EV1 e EV2) foram alimentadas com dietas contendo 24, 26, 28 e $30 \%$ de proteína bruta e 2900 kcal de energia metabolizável (Tab. 1) e pesadas semanalmente.

Os dados representam 5.256 pesagens registradas de codornas de corte das linhagens EV1 e EV2 no $21^{\circ}$ e $35^{\circ}$ dias de idade. Foram retirados registros de aves sem identificação de sexo ou com peso vivo abaixo ou acima de três desviospadrão em relação à média. $\mathrm{O}$ banco de dados utilizado apresentava a identificação do animal, pai, mãe, sexo, valor do peso à idade de avaliação e nível de proteína da dieta $(24,26,28$ e $30 \%$ ). O banco de dados foi dividido em quatro partes correspondentes à combinação de idade (21 e 35 dias) e linhagem (EV1 e EV2) para realização das análises. Cada um deles está descrito na Tab. 2. 
Utilização de modelos de norma...

Tabela 1. Composição das dietas experimentais para codornas de corte

\begin{tabular}{|c|c|c|c|c|}
\hline \multirow{2}{*}{ Ingrediente } & \multicolumn{4}{|c|}{ Nível de proteína bruta (\%) } \\
\hline & 24 & 26 & 28 & 30 \\
\hline Milho & 46,862 & 40,640 & 33,812 & 27,280 \\
\hline Farelo de soja & 42,087 & 47,461 & 53,112 & 58,620 \\
\hline Farelo de trigo & 4,000 & 4,000 & 4,000 & 4,000 \\
\hline Óleo de soja & 3,736 & 4,715 & 5,871 & 6,941 \\
\hline Calcário & 1,086 & 0,998 & 1,041 & 1,018 \\
\hline Fosfato bicálcico & 0,924 & 0,921 & 0,867 & 0,839 \\
\hline Sup. Min. e vit. ${ }^{1}$ & 0,500 & 0,500 & 0,500 & 0,500 \\
\hline Sal comum & 0,266 & 0,236 & 0,256 & 0,251 \\
\hline DL-metionina & 0,138 & 0,193 & 0,229 & 0,275 \\
\hline L-treonina & 0,102 & 0,136 & 0,162 & 0,195 \\
\hline Inerte & 0,300 & 0,200 & 0,150 & 0,080 \\
\hline Total & 100,00 & 100,00 & 100,00 & 100,00 \\
\hline \multicolumn{5}{|l|}{ Composição calculada } \\
\hline Proteína bruta $(\%)$ & 24,00 & 26,00 & 28,00 & 30,00 \\
\hline En. metab. (kcal/kg) & 2900 & 2900 & 2900 & 2900 \\
\hline Cálcio (\%) & 0,80 & 0,80 & 0,80 & 0,80 \\
\hline Fósforo disp. (\%) & 0,30 & 0,30 & 0,30 & 0,30 \\
\hline Met.+cistina (\%) & 0,87 & 0,99 & 1,05 & 1,14 \\
\hline Metionina (\%) & 0,60 & 0,68 & 0,74 & 0,81 \\
\hline Lisina $(\%)$ & 1,31 & 1,48 & 1,59 & 1,73 \\
\hline Treonina $(\%)$ & 1,02 & 1,13 & 1,24 & 1,35 \\
\hline
\end{tabular}

${ }^{1}$ Composição por kilo de produto: vit. $\mathrm{A}-2.000 .000 \mathrm{UI}$; vit. $\mathrm{D}_{3}-375.000 \mathrm{UI}$; vit $\mathrm{E}-3.750 \mathrm{mg}$; vit. $\mathrm{K}_{3}-500 \mathrm{mg}$; vit. $\mathrm{B}_{1}-50 \mathrm{mg}$; vit. $\mathrm{B}_{2}-750 \mathrm{mg}$; vit. $\mathrm{B}_{6}-500 \mathrm{mg}$; vit. $\mathrm{B}_{12}-3.750 \mathrm{mcg}$; niacina $-6.250 \mathrm{mg}$; ác. Pantotênico $-2.500 \mathrm{mg}$; biotina - 10mg; ác. fólico - 125mg; colina - 75.000mg; metionina - 250.000mg; selênio - 45mg; iodo - 175mg; ferro - 12.525mg; cobre - 2.500mg; manganês - 19.500mg; zinco - 13.750mg; avilamicina - 15.000mg; narasin 12.250mg; B.H.T. $-500 \mathrm{mg}$; vit. C $-12.500 \mathrm{mg}$.

Tabela 2. Descrição dos arquivos utilizados nas análises contendo pesos de codornas de corte EV1 e EV2 no $21^{\circ}$ e $35^{\circ}$ dias de idade

\begin{tabular}{lcccc} 
& & \multicolumn{3}{c}{ Grupo genético/Idade } \\
\cline { 2 - 5 } \multicolumn{1}{c}{ Itens } & \multicolumn{3}{c}{ EV1 } & \multicolumn{2}{c}{ EV2 } \\
\cline { 2 - 5 } & 21 dias & 35 dias & 21 dias & 35 dias \\
\hline Número de observações & 1467 & 1445 & 1180 & 1164 \\
Número de observações (24\% PB) & 600 & 601 & 516 & 518 \\
Número de observações (26\% PB) & 182 & 174 & 91 & 91 \\
Número de observações (28\% PB) & 383 & 388 & 190 & 192 \\
Número de observações (30\% PB) & 302 & 282 & 383 & 363 \\
Animais incluídos na matriz de parentesco & 1729 & 1709 & 1386 & 1371 \\
\hline
\end{tabular}

As análises foram realizadas sob modelo animal unicaracterístico com regressões aleatórias. Os efeitos fixos de sexo e genéticos aditivos aleatórios foram modelados como funções lineares de polinômios ortogonais de Legendre ponderados por coeficientes de regressão (fixos ou aleatórios, de acordo com o efeito). O mesmo modelo de avaliação foi utilizado nos quatro arquivos e foi definido como:

$$
y_{h i j}=\sum_{k=0}^{1} b_{j k} \phi_{k}\left(p_{i}\right)+\sum_{k=0}^{1} a_{h k} \phi_{k}\left(p_{i}\right)+e_{h i j},
$$

$y_{h i j}$ é a observação do animal $h$, do sexo $j$, alimentado com dieta de nível proteico $i ; b_{j k}$ é o coeficiente de regressão fixo associado ao polinômio Legendre $k$ atribuído ao sexo $j ; a_{h k}$ é o coeficiente de regressão aleatória $k$ de efeito genético aditivo direto atribuído ao animal $h$; $\phi_{k}\left(p_{i}\right)$ é o polinômio de Legendre $\mathrm{k}$ associado ao nível proteico $i$; e $e_{h i j}$ é o resíduo associado à observação $y_{h i j}$.

em que : 
$\mathrm{Na}$ forma matricial, este modelo é especificado como:

$$
y=X b+Z a+e,
$$

em que: $y$ é o vetor de observações; $b$ é o vetor de coeficientes de regressão fixos atribuídos a cada sexo; $a$ é o vetor de coeficientes de regressão aleatória atribuídos aos efeitos genéticos aditivos diretos; $X$ e $Z$ são matrizes de incidência de efeitos em b e a, contendo polinômios de Legendre relativos ao valor da variável controle adotada (PB); e $e$ é o vetor de resíduos do modelo.

A comparação de modelos que consideram a variância residual homogênea e heterogênea foi feita pelo critério de informação bayesiano ou BIC (Bayesian information criterion), proposto por Schwarz (1978) para cada arquivo formado. Este critério permite comparar modelos não

$$
\begin{aligned}
& E\left[\begin{array}{l}
y \\
a \\
e
\end{array}\right]=\left[\begin{array}{c}
X b \\
0 \\
0
\end{array}\right], \\
& G=\left[\begin{array}{cc}
\sigma_{b_{0}}^{2} & \sigma_{b_{0} b_{1}} \\
\sigma_{b_{0} b_{1}} & \sigma_{b_{1}}^{2}
\end{array}\right], \\
& V(y)=Z(A \otimes G) Z^{\prime}+R,
\end{aligned}
$$

$$
V\left[\begin{array}{l}
a \\
e
\end{array}\right]=\left[\begin{array}{cc}
G \otimes A & 0 \\
0 & R
\end{array}\right] \text {, em que: } R=\left[\begin{array}{cccc}
I_{n 1} \sigma_{e_{1}}^{2} & 0 & 0 & 0 \\
0 & I_{n 2} \sigma_{e_{2}}^{2} & 0 & 0 \\
0 & 0 & I_{n 3} \sigma_{e_{3}}^{2} & 0 \\
0 & 0 & 0 & I_{n 4} \sigma_{e_{4}}^{2}
\end{array}\right] \mathrm{e}
$$

$\sigma_{b_{0}}^{2}$ e $\sigma_{b_{1}}^{2}$ são os componentes de variância dos coeficientes de regressão do polinômio de Legendre relacionados ao intercepto e à inclinação da reta atribuída ao efeito genético aditivo direto, respectivamente; $\sigma_{b_{0} b_{1}}$ é o componente de covariância entre estes coeficientes de regressão; $\mathrm{R}$ é a matriz de variâncias residuais heterogêneas para quatro classes; e A é a matriz de numeradores dos coeficientes de Wright. No modelo que considera homocedasticidade residual, $R=I \sigma_{e}^{2}$. seguinte fórmula:

$\sigma_{a_{i j}}=Z_{i} G Z_{j}^{\prime}$, em que:

$Z_{i}=\left[\begin{array}{ll}\phi_{0}(i) & \phi_{1}(i)\end{array}\right]_{\mathrm{e}}$

$Z_{j}=\left[\begin{array}{ll}\phi_{0}(j) & \phi_{1}(j)\end{array}\right]$ aninhados e selecionar aqueles com bom ajuste e mais parcimoniosos, pois aplica fator de "penalização" proporcional ao número de parâmetros do modelo como forma de regularização:

$$
B I C=-2 \ln L+p \ln (n),
$$

em que: $L$ refere-se ao valor maximizado da função de verossimilhança do modelo ajustado; $p$ é o número de parâmetros livres a serem estimados; e $n$ é o número de observações ou tamanho da amostra.

Considerou-se a existência de heterogeneidade de variância residual em quatro diferentes classes formadas de acordo com os níveis da variável controle (24 a 25\%, 26 a 27\%, 28 a 29\%, 30 a $31 \%$ de $\mathrm{PB}$ ). Adicionalmente, assumiu-se que:

Para obtenção da covariância genética aditiva entre dois níveis proteicos $\mathrm{i}$ e $\mathrm{j}$, utilizou-se a

Também foi feita a estimativa da herdabilidade direta em função do nível de proteína bruta da dieta e classe de resíduo, da seguinte maneira:

$h_{d_{i}}^{2}=\frac{Z_{i} G Z_{i}^{\prime}}{Z_{i} G Z_{i}^{\prime}+\sigma_{e_{j}}^{2}}$, em que: $i$ representa o

nível proteico da dieta e $j$ refere-se à classe residual da qual este nível faz parte. 
Os componentes de covariância atribuídos a cada efeito aleatório foram estimados por meio do programa Wombat (2006), que utiliza o método da máxima verossimilhança restrita (REML). Funções de covariância foram utilizadas para estimar a estrutura de covariância genética aditiva e a herdabilidade direta em função dos níveis de proteína bruta da dieta e classe de variância residual. $\mathrm{O}$ critério de convergência adotado, definido pelo valor do quadrado das diferenças entre estimativas, foi $1 \times 10^{-11}$.

\section{RESULTADOS E DISCUSSÃO}

Os resultados referentes aos critérios de comparação de modelos estão descritos na Tab. 3. Todos os modelos que consideraram a heterogeneidade de variância residual para os quatro bancos de dados se mostraram melhores do que aqueles que consideraram a variância do resíduo homogênea dado o menor valor de BIC (Bayesian information criterion). Portanto, para a avaliação da interação genótipo-ambiente, foi adotado modelo que considerou diferentes valores de variância residual para quatro classes de proteína bruta. Outros autores também verificaram a necessidade de se considerar a heterogeneidade de variância residual em modelos para curva de crescimento, em diferentes espécies, pelo efeito de escala nas medidas tomadas em diferentes idades (Meyer, 2000; Sarmento et al., 2007; Sousa et al., 2008; Bonafé, 2008), produção de leite no dia do controle (EL Faro e Albuquerque,2003) e interação genótipo-ambiente para produção de leite no dia do controle em ambientes distintos (Calus et al., 2006).

Tabela 3. Comparação de modelos com heterogeneidade e homogeneidade de variância residual pelo critério de informação bayesiano (BIC)

\begin{tabular}{|c|c|c|c|c|c|}
\hline \multicolumn{2}{|c|}{$\begin{array}{l}\text { Arquivo } \\
\text { de dados }\end{array}$} & $\begin{array}{l}\text { Modelo quanto à var. } \\
\text { residual }\end{array}$ & $\begin{array}{c}\text { Número de } \\
\text { parâmetros (p) }\end{array}$ & $\begin{array}{c}\text { Função de máxima } \\
\text { verossimilhança }(\log L)\end{array}$ & BIC \\
\hline \multirow{4}{*}{ EV1 } & \multirow{2}{*}{21} & 1 Classe & 4 & $-4718,713$ & 9450,092 \\
\hline & & 4 classes & 7 & $-4678,075$ & 9378,315 \\
\hline & \multirow{2}{*}{35} & 1 Classe & 4 & $-5026,631$ & 10065,902 \\
\hline & & 4 classes & 7 & $-5018,420$ & 10058,059 \\
\hline \multirow{4}{*}{ EV2 } & \multirow{2}{*}{21} & 1 Classe & 4 & $-3675,552$ & 7363,392 \\
\hline & & 4 classes & 7 & $-3653,566$ & 7328,162 \\
\hline & \multirow{2}{*}{35} & 1 Classe & 4 & $-4034,633$ & 8081,530 \\
\hline & & 4 classes & 7 & $-4026,665$ & 8074,791 \\
\hline
\end{tabular}

Comparando-se as correlações genéticas entre os pesos nos diversos ambientes nutricionais, nota-se que, ao se considerar apenas uma classe de resíduo, os valores de correlação tendem a ser mais altos (Tab. 4, acima da diagonal) que no modelo com quatro classes de resíduo (abaixo da diagonal). Portanto, neste caso, o primeiro modelo indica interação genótipo-ambiente mais branda do que sugere o ajuste do segundo modelo para os níveis 24 e 28 (EV1 35 dias) e 24 e 30 (EV1 21 e 35 dias), no qual os valores de correlação genética estimados foram menores que 0,80 (Robertson, 1959). Isto mostra que para EV1 haverá mudança importante na ordem dos valores genéticos preditos sob diferentes níveis de proteína bruta da dieta, enquanto isso parece não ocorrer para EV2.

Estimativas dos componentes de (co)variância atribuídos aos coeficientes de regressão aleatória e às quatro classes de variância residual para os quatro bancos de dados analisados estão descritas na Tab. 5. De maneira geral, a variância estimada para o coeficiente de regressão aleatória do intercepto $\left(\mathrm{b}_{0}\right)$ é maior do que a estimada para o coeficiente de regressão aleatória linear $\left(b_{1}\right)$. Estes coeficientes apresentaram correlação positiva em todas as quatro análises, em diferentes graus: 0,64 (EV1- 21 dias de idade), 0,47 (EV1- 35 dias de idade), 0,92 (EV2- 21 dias de idade) e 0,98 (EV2- 35 dias de idade). Isto indica que quanto maior o valor do intercepto (valor genético predito para $27 \%$ de $\mathrm{PB}$ ), mais positiva será a inclinação na reta que descreve a sensibilidade das aves à mudança de ambiente. Maior distância da estimativa da correlação em relação ao valor 1 indica reordenamento mais intenso de valores genéticos nos diferentes ambientes ( $\mathrm{Su}$ et al., 2006). Resultados semelhantes foram apresentados por Santos et al. 
(2008) que, ao estudarem a sensibilidade de valores genéticos de codornas de corte às mudanças de proteína bruta com modelo de estrutura residual homogênea, encontraram maior associação entre $b_{0}$ e $b_{1}$ para a linhagem EV2. Os componentes de variância residual apresentaram grande modificação com a mudança de classes em todas as análises. A $2^{\mathrm{a}}$ classe, correspondente ao intervalo de 26 a $27 \%$ de proteína bruta, foi a que apresentou maior variância do resíduo, e a última classe (30-31\% de PB) a menor variância residual, indicando que a divisão em classes realmente pode levar à melhor partição da variação.

As estruturas de covariância genética aditiva direta em função do nível de PB bruta da dieta, estimadas para os dois grupos genéticos em ambas as idades de avaliação, estão apresentadas na Fig. 1. Observa-se que a estrutura de covariância genética aditiva direta apresenta inclinação em direção aos maiores valores de proteína bruta considerados, indicando presença de maior variação nos níveis de PB mais altos dentre os utilizados. Além disso, verifica-se também maior covariância para os maiores níveis de proteína bruta, evidenciada pela maior inclinação da superfície em direção a estes valores nos eixos correspondentes. A forma da superfície de representação da estrutura de (co)variância apresentou-se semelhante nas diferentes idades dentro de cada linhagem, desconsiderando-se a escala. Foi observada mudança nos valores de (co)variância do efeito genético aditivo em todas as combinações grupo genético e idade com a mudança do nível proteico da dieta, o que mostra a utilidade das funções de covariância para este tipo de estudo.

Tabela 4. Estimativas das correlações genéticas entre os pesos nos diferentes níveis de proteína bruta considerando-se homogeneidade de variância residual (acima da diagonal) e heterogeneidade de variância residual (abaixo da diagonal)

\begin{tabular}{|c|c|c|c|c|}
\hline \multicolumn{5}{|c|}{ EV1 ao $21^{\circ}$ dia de idade } \\
\hline Nível de PB & 24 & 26 & 28 & 30 \\
\hline 24 & - & 0,999 & 0,996 & 0,992 \\
\hline 26 & 0,935 & - & 0,999 & 0,996 \\
\hline 28 & 0,817 & 0,968 & - & 0,999 \\
\hline 30 & 0,710 & 0,913 & 0,986 & - \\
\hline \multicolumn{5}{|c|}{ EV1 ao $35^{\circ}$ dia de idade } \\
\hline Nível de PB & 24 & 26 & 28 & 30 \\
\hline 24 & - & 0,978 & 0,918 & 0,837 \\
\hline 26 & 0,930 & - & 0,981 & 0,933 \\
\hline 28 & 0,779 & 0,955 & - & 0,985 \\
\hline 30 & 0,631 & 0,872 & 0,978 & - \\
\hline \multicolumn{5}{|c|}{ EV2 ao $21^{\circ}$ dia de idade } \\
\hline Nível de PB & 24 & 26 & 28 & 30 \\
\hline 24 & - & 0,999 & 0,997 & 0,995 \\
\hline 26 & 0,986 & - & 0,999 & 0,998 \\
\hline 28 & 0,966 & 0,995 & - & 1,000 \\
\hline 30 & 0,948 & 0,987 & 0,998 & - \\
\hline \multicolumn{5}{|c|}{ EV2 ao $35^{\circ}$ dia de idade } \\
\hline Nível de PB & 24 & 26 & 28 & 30 \\
\hline 24 & - & 1 & 0,999 & 0,998 \\
\hline 26 & 0,999 & - & 1 & 0,999 \\
\hline 28 & 0,998 & 1 & - & 1 \\
\hline 30 & 0,996 & 0,999 & 1 & - \\
\hline
\end{tabular}


Tabela 5. Componentes de variância atribuídos aos coeficientes de regressão do intercepto $\left(b_{0}\right)$ e linear $\left(b_{1}\right)$ do efeito genético aditivo direto em função dos níveis proteicos e classes de variância residual para cada classe estimados para as linhagens EV1 e EV2 no $21^{\circ}$ e $35^{\circ}$ dias de idade

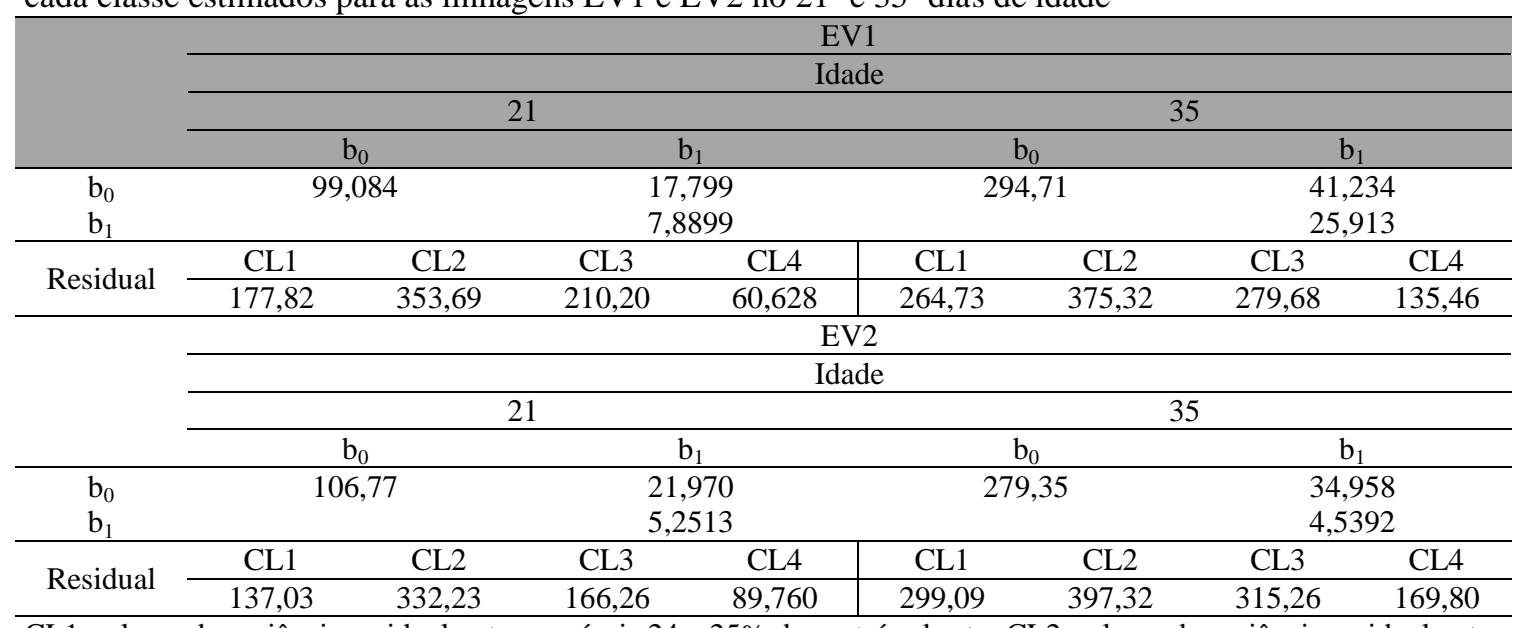

CL1 - classe de variância residual entre os níveis 24 e $25 \%$ de proteína bruta; CL2 - classe de variância residual entre os níveis 26 e $27 \%$ de proteína bruta; CL3 - classe de variância residual entre os níveis 28 e $29 \%$ de proteína bruta; CL4 - classe de variância residual entre os níveis 30 e $31 \%$ de proteína bruta

As estimativas de herdabilidade para os grupos genéticos EV1 e EV2 nas diferentes idades estão apresentadas na Fig. 2. Houve mudança no valor de herdabilidade para todas as idades/linhagens com a mudança no nível de proteína bruta. Em razão da utilização de modelo que considera classes residuais, é possível identificar visualmente a divisão das mesmas pela descontinuidade na função. Isto ocorre em decorrência do valor diferenciado do componente de variância residual, que entra como denominador na estimativa do valor de $\mathrm{h}^{2}$, e, como consequência, os menores valores de herdabilidade, em todas as figuras (Fig. 2a, b, c e d), estão compreendidos no intervalo de 26 a $27 \%$ de PB, no qual o valor de variância residual foi maior. Considerando-se os valores de herdabilidade dentro de cada intervalo de classe de resíduo, a tendência dos estimadores deste parâmetro é crescente, isto é, aumenta gradualmente, em maior ou menor escala, com o aumento do nível proteico. Para ambos os grupos genéticos, o valor da herdabilidade tendeu a ser mais alto no $35^{\circ}$ dia de idade do que no $21^{\circ}$ dia de idade, considerando-se as diferentes classes residuais. Portanto, a utilização do valor genético ao $35^{\circ}$ dia de idade no critério de seleção seria a mais indicada com base na maior intensidade de resposta à seleção em relação à variância fenotípica. Houve também forte variação nos valores de herdabilidade em função dos níveis de proteína da dieta, ou seja, aumento de $\mathrm{h}^{2}$ com o aumento de PB da dieta, o que também causaria maior resposta à seleção em relação à variância fenotípica. Santos et al. (2008) chegaram a conclusões semelhantes acerca da herdabilidade, porém considerando homogeneidade de variância residual, sendo a mudança em $\mathrm{h}^{2}$ consequência apenas da mudança na variância genética aditiva nos diferentes níveis proteicos.

As normas de reação de 25 codornas amostradas aleatoriamente em cada uma das quatro análises são apresentadas na Fig. 3. Houve heterogeneidade de sensibilidade dos valores genéticos submetidos à mudança no nível nutricional em todas as análises combinando idade e grupo genético. A linhagem EV1 apresentou mudança na ordem dos efeitos genéticos preditos em diferentes níveis de proteína bruta da dieta, tanto ao $21^{\circ}$ quanto ao $35^{\circ}$ dia de idade, o que já era esperado em decorrência dos valores de correlação genética e dos coeficientes de regressão aleatória. As normas de reação do grupo genético EV2 apresentam apenas aumento na dispersão dos valores genéticos com o aumento do nível proteico, não havendo reordenamento de valores genéticos. Portanto, os resultados indicam a presença de interação genótipo-ambiente para ambos os grupos genéticos, seja pelo reordenamento dos valores genéticos ou pelo aumento na dispersão deles. 

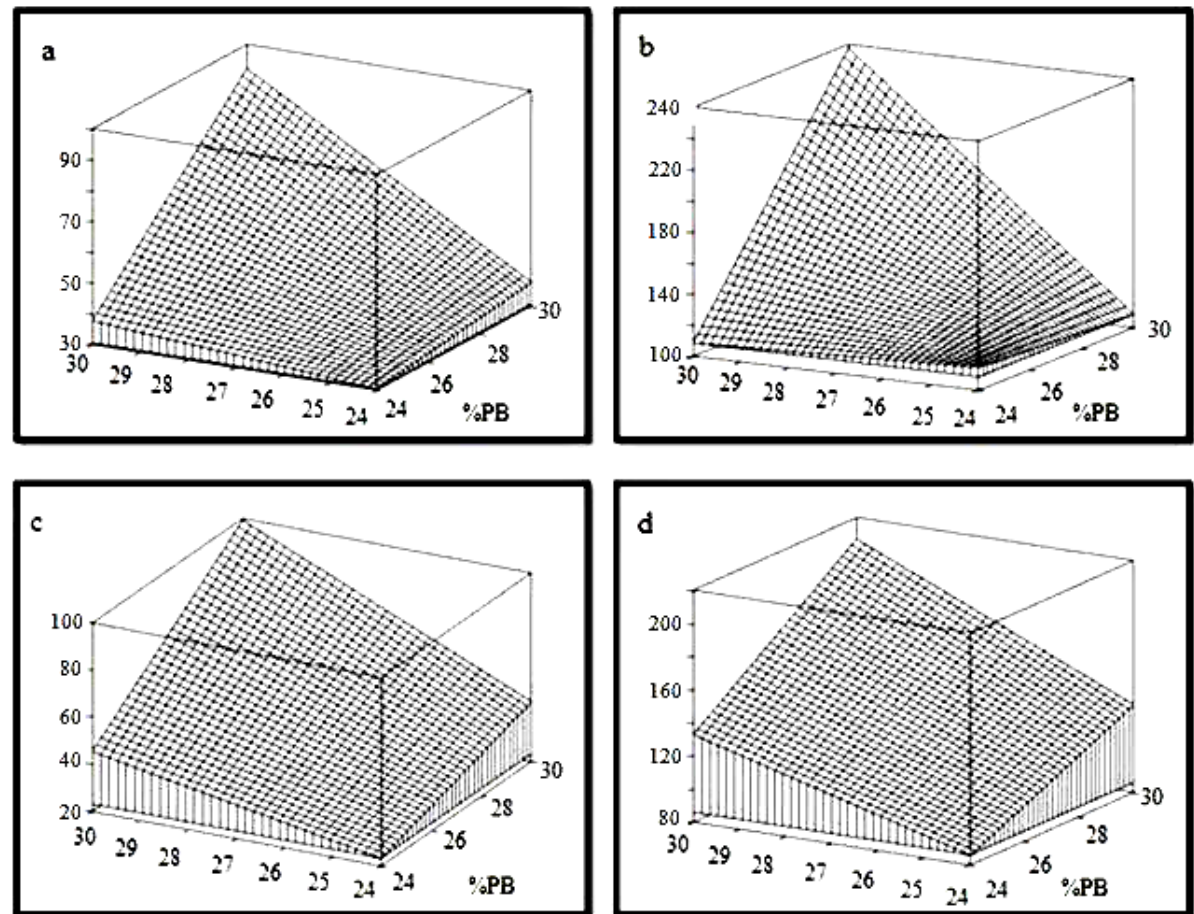

Figura 1. Estrutura de covariância $\left(\mathrm{gr}^{2}\right)$ do efeito genético aditivo direto em função do nível de proteína bruta da dieta estimada no $21^{\circ}$ e $35^{\circ}$ dias de idade para os grupos genéticos EV1 e EV2 (a:EV1-21 dias; b:EV1-35dias; c:EV2-21 dias e d:EV2-35 dias).
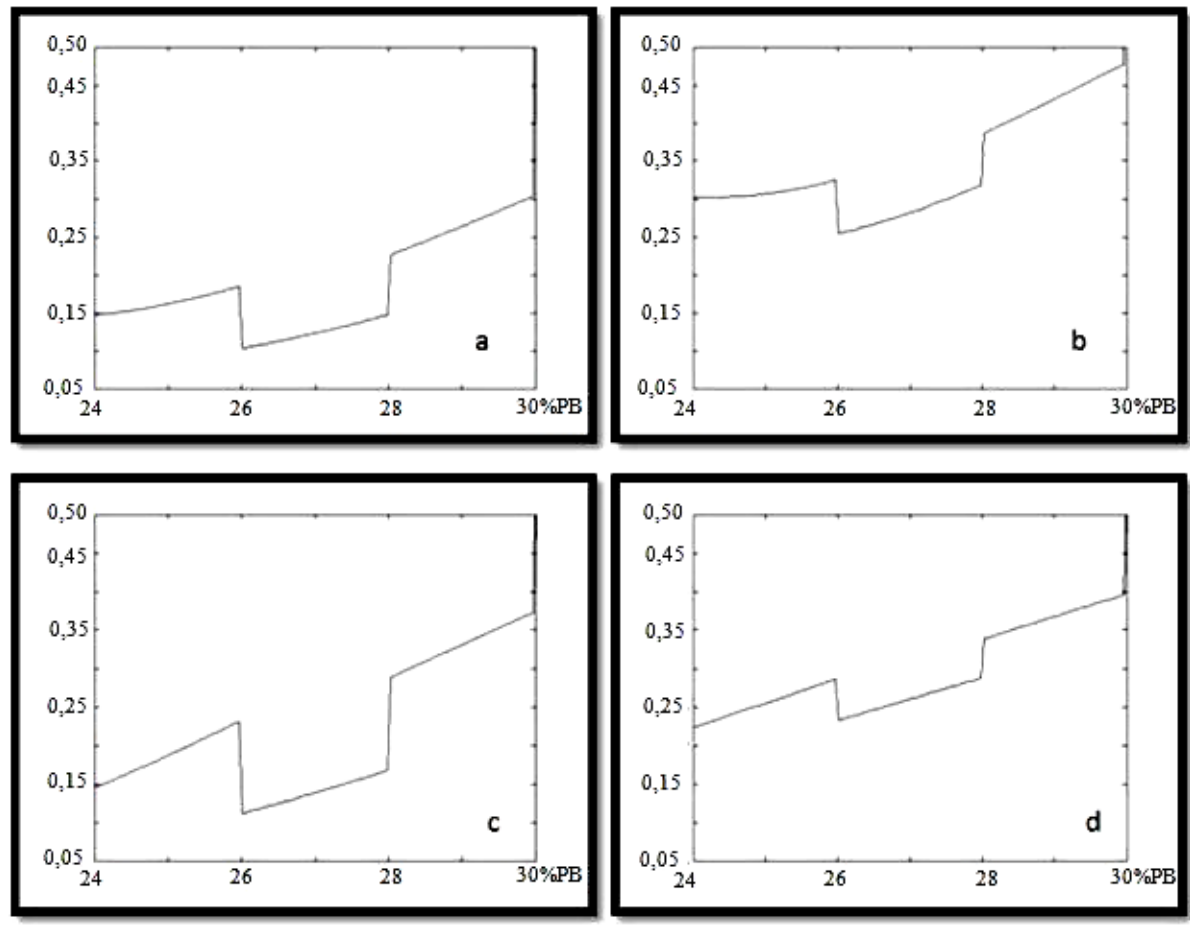

Figura 2. Herdabilidades diretas estimadas dos pesos ao $21^{\circ}$ e $35^{\circ}$ dias de idade de codornas de corte das linhagens EV1 e EV2 em função do nível de proteína bruta da dieta (a:EV1-21 dias; b:EV1-35dias; c:EV2-21 dias e d:EV2-35 dias). 

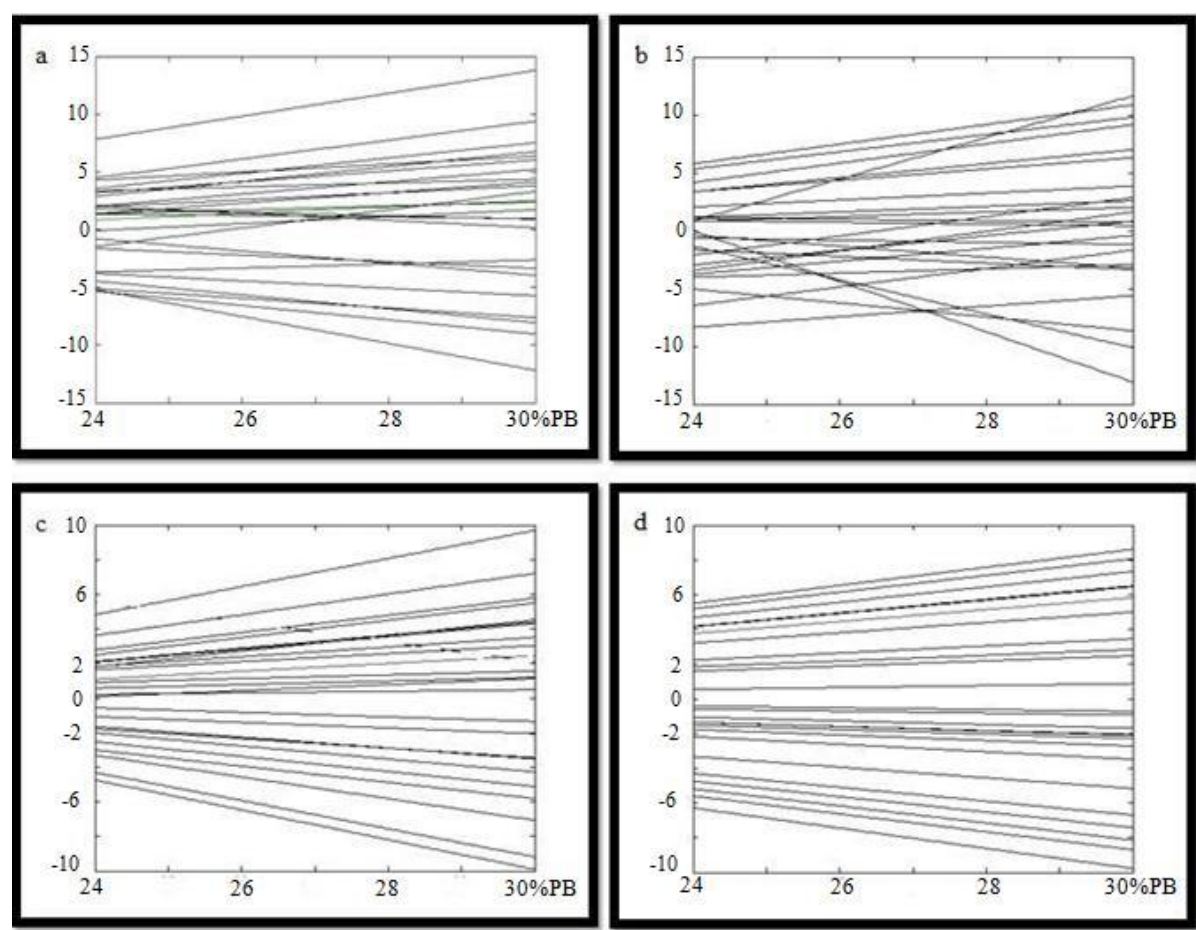

Figura 3. Normas de reação de valores genéticos aditivos de 25 indivíduos da população amostrados aleatoriamente (a:EV1-21 dias; b:EV1-35dias; c:EV2-21 dias e d:EV2-35 dias)

\section{CONCLUSÕES}

Modelos de regressão aleatória que consideram heterocedasticidade residual são melhores do que os que consideram a variância residual homogênea para estudo da sensibilidade dos valores genéticos de codornas de corte alimentadas com dietas contendo diferentes níveis de proteína bruta. Houve interação valor genético x nível de PB da dieta para EV1 e EV2 nas duas idades de avaliação $\left(21^{\circ}\right.$ e $35^{\circ}$ dias de idade), a primeira pelo reordenamento dos valores genéticos e aumento na dispersão da variância dos valores genéticos, e a segunda apenas pelo aumento na dispersão. A predição dos valores genéticos deve ser feita para codornas alimentadas com dietas contendo nível de proteína bruta similar ao que será utilizado em explorações comerciais de codornas de corte.

\section{REFERÊNCIAS}

BONAFÉ, C.M. Avaliação do crescimento de codornas de corte utilizando modelos de regressão aleatória. 2008. 58f. Dissertação (Mestrado em Genética e Melhoramento) - Universidade Federal de Viçosa, Viçosa. 2008.
CALUS, M.P.L; POOL, M.H.; VEERKAMP, R.F. Heterogeneous variances and genotype $\mathrm{x}$ environment interaction in a random regression test-day model. In: WORLD CONGRESS ON GENETICS APLIED TO LIVESTOCK PRODUCTION, 2006, Belo Horizonte. Proceedings... $8^{\text {th }}$ World Congress on Genetics Applied to Livestock Production, 2006. (CD-ROM).

EL FARO, L.; ALBUQUERQUE, L.G. Utilização de modelos de regressão aleatória para produção de leite no dia do controle, com diferentes estruturas de variâncias residuais. Rev. Bras. Zootec., v.32, p.11041113, 2003.

FALCONER, D.S.; MACKAY, T.F.C. Introduction to quantitative genetics. 4.ed. London: Longman. 1996.

JONG, G. Quantitative genetics of reaction norms. $J$. Evolut. Biol., v.3, p.447-468, 1990.

KIRKPATRICK, M.; LOFSVOLD, D.; BULMER, M.; Analysis of the inheritance, selection and volution of growth trajectories. Genetics, v.124, p.979-993, 1990.

KOLMODIN, R. Reaction norms for the study of genotype by environment interaction in animal breeding. Uppsala: Swedish University of Agricultural Sciences, 2003. 35p. Doctoral thesis. Department of Animal Breeding and Genetics, 2003. 
MEYER, K. Random regressions to model phenotypic variation in monthly weights of Australian beef cows. Livest. Prod. Scie., v.65, p.19-38, 2000.

MEYER, K. "WOMBAT" - Digging deep for quantitative genetic analyses by restricted maximum likelihood. In: WORLD CONGRESS ON GENETIC APPLIED TO LIVESTOCK PRODUCTION, 8., 2006, Belo Horizonte. Proceedings... Belo Horizonte, 2006. (CD-ROM).

ROBERTSON, A. The sampling variance of the genetic correlation coefficient. Biometrics, v.15, p.469-485, 1959.

SANTOS, G.G.; CORRÊA, G.S.S.; VALENTE, B.D. et al. Sensibilidade de valores genéticos de codornas de corte em crescimento às modificações de níveis de proteína das dietas. Arq. Bras. Med. Vet. Zootec.,v.60, p.1188-1196, 2008.
SARMENTO, J.L.R. Modelos de regressão aleatória para avaliação genética da curva de crescimento de ovinos da raça Santa Inês. 2007. 101f. Tese (Doutorado em genética e melhoramento) Universidade Federal de Viçosa, Viçosa, MG.

SCHWARZ, G. Estimating the dimension of a models. The Annals of Statistics, v.6, 1978, p.461-464.

SOUSA, J.E.R.; SILVA, M.A.; SARMENTO, J.L.R. et al. Homogeneidade e heterogeneidade de variância residual em modelos de regressão aleatória sobre o crescimento de caprinos Anglo-Nubianos. Pesq. Agrop. Bras., v.43, p.1725-1732, 2008.

SU, G.; MADSEN P.; LUND M. S. et al. Bayesian analysis of the linear reaction norm model with unknown covariates. J. Anim. Sci., v.84, p.1651-1657, 2006. 